\title{
Corrigendum
}

\section{Corrigendum to "Phytochemical Composition and Chronic Hypoglycemic Effect of Bromelia karatas on STZ-NA-Induced Diabetic Rats"}

\author{
Sonia M. Escandón-Rivera $(\mathbb{D}$, Adolfo Andrade-Cetto $(\mathbb{D}$, and Gabriela Sánchez-Villaseñor \\ Laboratorio de Etnofarmacología, Facultad de Ciencias, Universidad Nacional Autónoma de México, \\ 4510 Ciudad de México, Mexico \\ Correspondence should be addressed to Adolfo Andrade-Cetto; aac@ciencias.unam.mx \\ Received 29 May 2021; Accepted 29 May 2021; Published 14 June 2021 \\ Copyright (C) 2021 Sonia M. Escandón-Rivera et al. This is an open access article distributed under the Creative Commons \\ Attribution License, which permits unrestricted use, distribution, and reproduction in any medium, provided the original work is \\ properly cited.
}

In the article titled "Phytochemical Composition and Chronic Hypoglycemic Effect of Bromelia karatas on STZNA-Induced Diabetic Rats" [1], the authors wish to additionally acknowledge DGAPA-UNAM for the postdoctoral scholarship provided to Sonia M. Escandón-Rivera. The revised acknowledgments statement is as follows:

\section{Acknowledgments}

The authors acknowledge M. C. Ramiro Cruz-Durán for the plant determination and M. C. Christian Alan
Cabello-Hernández for handling the animals at the Bioterium. This project was partially sponsored by DGAPA, PAPIIT IN228216, and PAPIIT IN226719. SER gratefully acknowledges DGAPA-UNAM for her postdoctoral scholarship.

\section{References}

[1] S. M. Escandón-Rivera, A. Andrade-Cetto, and G. SánchezVillaseñor, "Phytochemical composition and chronic hypoglycemic effect of Bromelia karatas on STZ-NA-induced diabetic rats," Evidence-Based Complementary and Alternative Medicine, vol. 2019, Article ID 9276953, 9 pages, 2019. 